\author{
B. Liljeström · K. Aktan-Collan • B. Isomaa • \\ L. Sarelin · A. Uutela $\cdot$ L. Groop · H. Kääriäinen · \\ T. Tuomi
}

\title{
Genetic testing for maturity onset diabetes of the young: uptake, attitudes and comparison with hereditary non-polyposis colorectal cancer
}

Received: 2 June 2004 / Accepted: 31 August 2004 / Published online: 20 January 2005

(C) Springer-Verlag 2005

\begin{abstract}
Aims/hypothesis: Mutations in hepatic nuclear factor $1 \alpha$ cause a monogenic form of diabetes, maturity onset diabetes of the young type 3 (MODY3). Our aim was
\end{abstract}

B. Liljeström · T. Tuomi

Department of Medicine, Helsinki University Hospital,

Helsinki, Finland

B. Liljeström · T. Tuomi

Research Program for Molecular Medicine, University of Helsinki,

Helsinki, Finland

B. Liljeström $\cdot$ B. Isomaa $\cdot$ T. Tuomi

Folkhälsan Genetic Institute, Folkhälsan Research Center, Helsinki, Finland

B. Liljeström · K. Aktan-Collan · H. Kääriäinen Department of Medical Genetics, The Family Federation of Finland,

Helsinki, Finland

B. Liljeström $(\square)$

Biomedicum Helsinki,

Botnia, B330b,

PO Box 700, 00029 Helsinki, Finland

e-mail: brita.liljestrom@hus.fi

Tel.: +358-9-47171909

Fax: +358-9-471921

B. Isomaa $\cdot$ L. Sarelin

Jakobstad Hospital,

Jakobstad, Finland

A. Uutela

The National Public Health Institute (KTL),

Helsinki, Finland

L. Groop

Department of Endocrinology, Lund University,

Malmö, Sweden

H. Kääriäinen

Department of Medical Genetics, University of Turku,

Turku, Finland

H. Kääriäinen

Department of Paediatrics, Turku University Hospital,

Turku, Finland
(1) to assess the uptake of genetic testing for MODY3 and to determine factors affecting it, and (2) to compare attitudes to predictive genetic testing between families with MODY3 and a previously studied group at risk of hereditary nonpolyposis colorectal cancer (HNPCC). Methods: Adult members of two extended MODY3 pedigrees, either with diabetes or a $50 \%$ risk of having inherited the mutation ( $n=144$, age $18-60$ years), were invited to an educational counselling session followed by a possibility to obtain the gene test result. Data were collected through questionnaires before counselling and 1 month after the test disclosure. Results: Eighty-nine out of $144(62 \%)$ participated in counselling, and all but one wanted the test result disclosed. No significant sociodemographic differences were observed between the participants and non-participants. The counselling uptake was similar among diabetic and nondiabetic subjects. Uncertainty about the future and the risk for the children were the most common reasons to take the gene test. At follow-up, most subjects in both MODY3 $(100 \%)$ and HNPCC $(99 \%)$ families were satisfied with their decision to take the test and trusted the result. The majority of both diabetic and non-diabetic subjects considered that the MODY3 gene test should be offered either in childhood (50 and $37 \%$ ) or as a teenager ( 30 and $37 \%$ ). Conclusions: Genetic testing for MODY3 was well accepted among both diabetic and non-diabetic participants. The subjects found the gene test reliable and they were satisfied with their decision regarding the predictive test.

Keywords Genetic testing - Maturity onset diabetes of the young (MODY3) · Hereditary non-polyposis colorectal cancer (HNPPC) · Test uptake and satisfaction

Abbreviations HD: Huntington's disease - HNF-1 $\beta$ : Hepatocyte nuclear factor- $1 \beta \cdot$ HNF- $1 \alpha$ : Hepatocyte nuclear factor- $1 \alpha \cdot \mathrm{HNF}-4 \alpha$ : Hepatocyte nuclear factor$4 \alpha \cdot$ HNPCC: Hereditary non-polyposis colorectal cancer . IPF: Insulin promoting factor-1 - MLH1: Human mutL (E.coli) homologue 1 - MODY: Maturity-onset diabetes of the young - STAI: State-Trait Anxiety Inventory 


\section{Introduction}

Maturity-onset diabetes of the young (MODY) is a group of monogenic forms of diabetes inherited in an autosomal dominant fashion. To date, mutations have been identified in the genes for hepatocyte nuclear factors $(H N F) 4 \alpha, 1 \alpha$, $1 \beta$ and NeuroD1 (neurogenic differentiation 1) causing MODY1, 3, 5 and 6, respectively, and in the glucokinase and insulin promoting factor (IPF) genes causing MODY2 and 4 [1-6]. After the cloning of the $H N F-1 \alpha$ (MODY3) gene on chromosome 12 in 1996 [2], more than 150 different mutations in the gene have been reported. The most common mutation is the Pro291fsinsC mutation, which arises in a mutational hot spot of the $H N F-1 \alpha$ gene [7]. Finding the mutation in a family provides an opportunity for predictive and diagnostic genetic testing for high-risk individuals in the family.

Predictive genetic testing of a large number of persons at risk has been limited mainly to progressive neurological diseases and hereditary cancer. Although pre-symptomatic testing for Huntington's disease has been available for over a decade, its uptake has in most countries been only $10-15 \%[8,9]$. Predictive testing for some forms of cancer, including hereditary nonpolyposis colorectal cancer (HNPCC), has been available since 1995 [10, 11]. HNPCC mutation carriers are estimated to have an $80 \%$ lifetime risk of colorectal cancer and an additional risk of extra-colonic malignancies, especially endometrial cancer [12-14]. In a large Finnish study, the uptake for a predictive test for HNPCC was remarkably high: $75 \%$ of all individuals at risk and $96 \%$ of those who attended counselling wanted the test [15]. However, a lower uptake rate of $43 \%$ was reported from the United States [16].

MODY3 is characterised by a low renal threshold for glucose and a poor insulin response to glucose [17, 18]. The beta cells are, however, able to secrete insulin in response to other secretagogues [19]. This, in conjunction with particularly good insulin sensitivity $[17,18]$, results frequently in hypoglycaemia in patients treated with either oral hypoglycaemic agents or insulin. The degree of insulin deficiency and the age at diagnosis of MODY3 diabetes can vary widely even within the same family [17]. Most patients are eventually treated with insulin or oral hypoglycaemic agents but treatment with diet is often sufficient in the early stages.

What could be the benefits of diagnostic or predictive genetic testing in MODY3? MODY is estimated to cover $1-4 \%$ of all diabetes, but no genetic epidemiological data exist to prove the true prevalence. The diagnosis is difficult to make on a clinical basis in sporadic cases with insufficient information on family history. Individuals carrying the Pro291fsinsC mutation are estimated to have an at least 95\% lifetime risk of MODY3 diabetes [20] and diabetes is often precipitated by pregnancy in unaffected mutation carriers. The benefits of correct diagnosis include the possibility to individualise treatment to avoid hypoglycaemia, to recognise the risk in the family and commencement of early treatment with insulin during pregnancy to avoid foetal problems. Although MODY3 has been con- sidered a mild form of diabetes, it can lead to severe microvascular complications depending mainly on the $\mathrm{HbA1c}$ level during lifetime [21]. Of note, the glucose tolerance deteriorates in most cases already during the pubertal years [20, 22, 23], although the diagnosis is often made much later. Thus, correct prediction of MODY3 may benefit prevention of complications. A predictive test can also relieve unnecessary worry. However, there is a risk of adverse effects, such as increased anxiety, uncertainty about the future, feelings of guilt, or difficulty in finding a new life perspective after learning that one has not inherited the feared gene $[9,24]$.

Despite increasing clinical interest in genetic testing of MODY, the acceptance of this in the families concerned has not been systematically studied. The only published case report suggested positive attitude [25]. In this study, we investigated the acceptance of a diagnostic or predictive genetic test for MODY3 diabetes. The diabetic subjects were offered the test to distinguish MODY3 from the more common forms of diabetes. The non-diabetic subjects were offered a predictive test. The aims were (1) to assess the uptake of genetic testing for MODY3 and to determine factors affecting it, and (2) to compare attitudes to predictive genetic testing between families with MODY3 and a previously studied group at risk of HNPCC [15].

\section{Subjects and methods}

The study included two Finnish extended pedigrees with the Pro291fsinsC mutation in the $H N F-1 \alpha$ gene identified in the Botnia study, which is a population-based study aiming at the identification of genes increasing susceptibility to type 2 diabetes [26]. During 2002-2003, we offered the family members genetic counselling and the possibility to obtain their earlier screened gene test result if they were either affected with diabetes or had a $50 \%$ risk of having inherited the mutation. Subjects were considered eligible if they were aged $18-60$ years and did not have any cognitive disorder that precluded informed consent. Those living abroad and individuals that previously had declined further contact were excluded. The subjects were approached through a letter including a consent form (Fig. 1). Those who refused to participate or did not return the consent form after two reminders were not contacted further. Pre-test questionnaires were sent to those consenting, and those returning the questionnaire were invited to a counselling session conducted by a medical geneticist (BL) at or near the subject's place of residence. A second questionnaire was sent 1 month after the counselling session and test result disclosure. The subjects gave informed consent to the study. The ethics committee of the Helsinki University Central Hospital approved the study and it was carried out in accordance with the Declaration of Helsinki as revised in 2000 .

Counselling The same medical geneticist (BL) performed the counselling and disclosed the test results for all subjects. The interactive semi-structured counselling included 


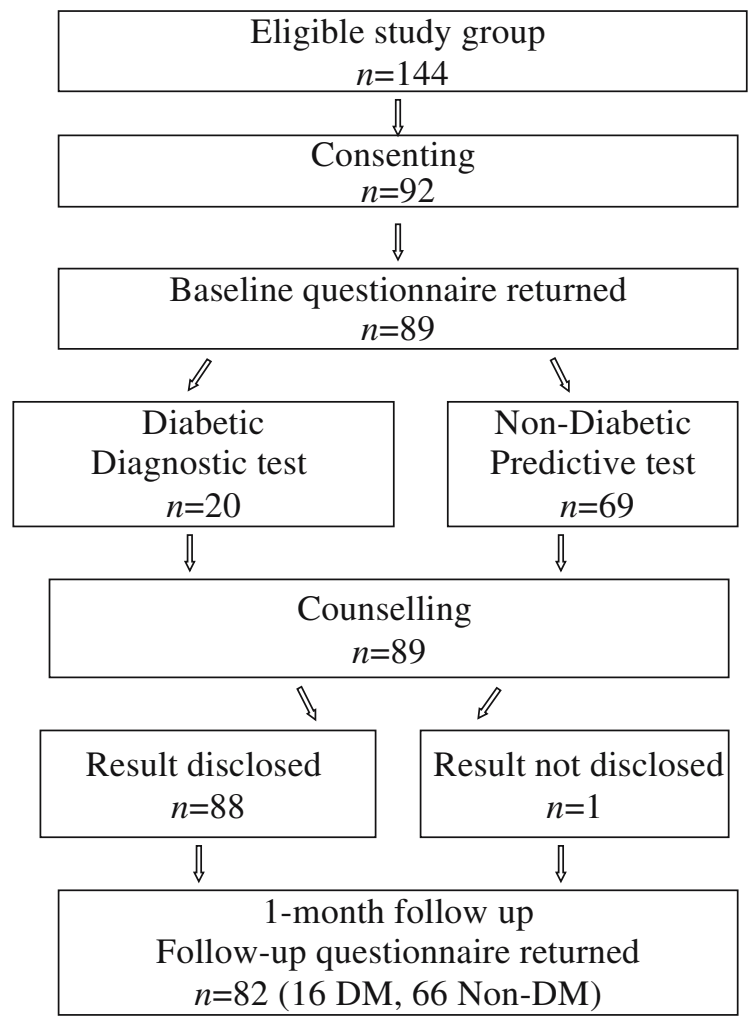

Fig. 1 Flow chart of the testing procedure information about MODY3, its mode of inheritance, the nature of the gene defect, risk of MODY3, and the methods available for follow-up and early detection of MODY3. The benefits and disadvantages of either the diagnostic or predictive gene test were discussed. The counsellees were then asked to consider whether they wanted test disclosure, either during the same day after a short break or after a 2week period of consideration. The test result was disclosed either individually or in the presence of an accompanying person, and its implications were discussed with the medical geneticist. For non-diabetic individuals having the mutation, the resulting high risk of diabetes was reiterated and individual surveillance was planned. For those already diabetic the MODY3 diagnosis was confirmed and suitable clinical surveillance was planned. Subjects who did not have the mutation were reminded of the general risk of diabetes in the population to prevent any false reassurance. The result and its interpretations were also given in written form.

The data for the non-diabetic subjects participating in the predictive genetic testing were compared with previously published data from a study on HNPCC [15]. The HNPCC study conducted from 1995 to 1998 included 36 families with three different mutations in the MLH1 gene. Subjects were considered eligible for the study if they were at $50 \%$ risk of having inherited the predisposing gene, aged 18 or older, without cancer diagnosis, and without any cognitive

Table 1 Comparison of the diabetic (DM) and non-diabetic (non-DM) subjects stratified according to whether they participated or did not participate in the MODY3 gene test study

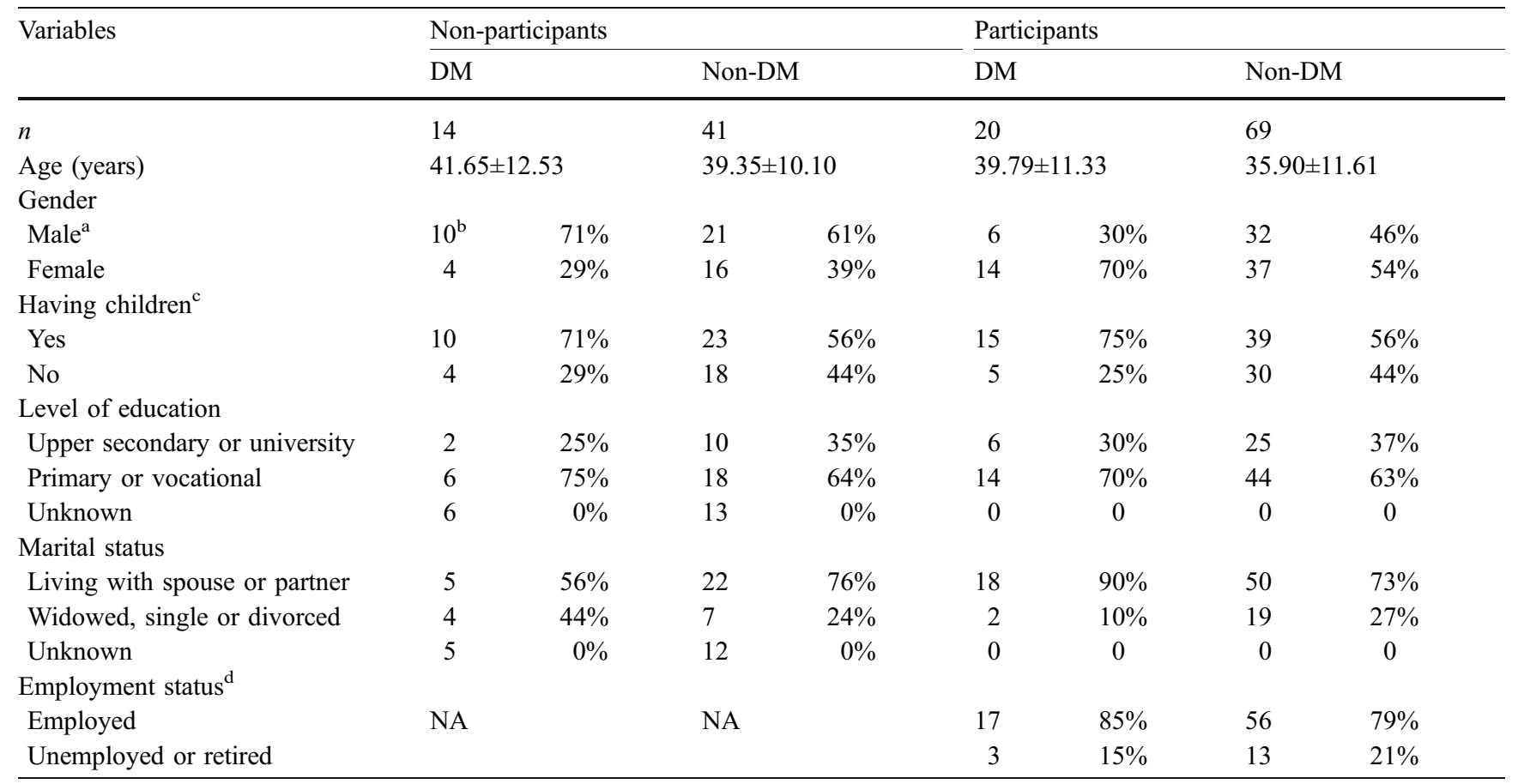

Data are given as mean \pm SD or $n(\%)$.

NA, the corresponding frequencies for the general Finnish population in the age group 15-74 years in 1997-2003 were not available ${ }^{a}$ The corresponding frequency for the general Finnish population in the age group 15-74 years in 1997-2003 is 48\% (http://www.stat.fi). $\mathrm{b}_{p}=0.04$, diabetic participants vs. non-participants

${ }^{c}$ The corresponding frequency for the general Finnish population in the age group 15-74 years in 1997-2003 is 42\% (http://www.stat.fi)

${ }^{\mathrm{d}}$ The corresponding frequency for the general Finnish population in the age group 15-74 years in 1997-2003 is 70\% (http://www.stat.fi) 
disorder that precluded informed consent. In the HNPCC study, the first counselling session preceded taking the DNA sample for the gene test while in the MODY3 study the samples had already been taken during the Botnia study. For the present analysis, subjects older than 60 years were excluded from the HNPCC cohort.

Questionnaires The study was based on two questionnaires modified from the study of Aktan-Collan et al. [15], which were filled in by the subjects twice, before (pre-test) and 1 month after (follow-up) the counselling. They included questions on social and demographic background (Table 1), life situation, health status, anxiety [the StateTrait Anxiety Inventory (STAI)] [27], as well as knowledge about MODY and attitudes to genetic or predictive genetic testing. Questions on pre-test risk perception (i.e. risk of having MODY3) were included in the pre-test questionnaire and questions regarding confidence in the test result, satisfaction about taking the test and reasons for taking it in the follow-up questionnaire. Most questions were presented as lists of choices with a possibility to also add a free alternative. In addition to self-reported data obtained through the questionnaires, data on the sociodemographic background variables for those not returning the questionnaires was retrieved from the Botnia database.
Statistical analyses Analyses were performed with Biomedical Data Processing statistical software (BMDP; Los Angeles, CA, USA). We used the Fisher's exact or chisquared test, with Yates' continuation correction when appropriate, for comparison of group frequencies, and the Mann-Whitney $U$-test for comparison of group means. Uncorrected $p$ values are presented. A $p$ value of less than 0.05 was considered statistically significant.

\section{Results}

Of the 144 eligible subjects, $92(64 \%)$ consented to participate in the study and $89(62 \%)$ returned the baseline questionnaire and attended the counselling session (Fig. 1). The study was divided into a diagnostic part (20 diabetic subjects) and a predictive part (69 non-diabetic subjects). Altogether 16 (80\%) diabetic and 66 (95\%) non-diabetic subjects replied to the follow-up questionnaire 1 month after the test disclosure.

A comparison of those who accepted $(n=89)$ or declined participation $(n=55)$ in the study is shown in Table 1 . Women participated more often than men did (51/71, 72\% vs. $38 / 69,55 \% ; p=0.06$ ), especially among the diabetic subjects $(14 / 18$ vs. $6 / 16, p=0.042)$. There were no significant sociodemographic differences between those partici-
Table 2 The subjects' knowledge about MODY3 diabetes before the counselling session stratified according to whether they had (DM) or did not have (non-DM) diabetes
$D M 1$ type 1 diabetes, $D M 2$ type 2 diabetes

${ }^{a}$ Comparison of non-diabetic vs. diabetic subjects for three to four choices $(d f=2-3)$

\begin{tabular}{|c|c|c|c|c|c|}
\hline \multirow[t]{2}{*}{ Question } & \multicolumn{2}{|l|}{ DM } & \multicolumn{2}{|l|}{ Non-DM } & \multirow{2}{*}{ value } \\
\hline & Numbe & r Percentage & Number & Percentage & \\
\hline MODY3 & & & & & 0.054 \\
\hline 1. Resembles DM1 & 1 & $5 \%$ & 4 & $6 \%$ & \\
\hline 2. Resembles DM2 & 6 & $30 \%$ & 12 & $17 \%$ & \\
\hline 3. Is a specific type of diabetes & 9 & $45 \%$ & 16 & $23 \%$ & \\
\hline 4. Cannot say & 4 & $20 \%$ & 37 & $54 \%$ & \\
\hline Insulin treatment is needed in MODY3 & & & & & 0.005 \\
\hline 1. Always at some stage of the disease & 0 & & 3 & $4 \%$ & \\
\hline 2. Usually not needed & 0 & & 1 & $1 \%$ & \\
\hline 3. Variable & 18 & $90 \%$ & 25 & $37 \%$ & \\
\hline 4. Cannot say & 2 & $10 \%$ & 39 & $57 \%$ & \\
\hline $\begin{array}{l}\text { The risk for late-onset complications (eye, nerve, } \\
\text { kidney) in MODY3 in comparison with DM1 is }\end{array}$ & & & & & 0.005 \\
\hline 1. Equal & 1 & $5 \%$ & 5 & $7 \%$ & \\
\hline 2. Smaller & 7 & $35 \%$ & 2 & $3 \%$ & \\
\hline 3. Greater & 2 & $10 \%$ & 11 & $16 \%$ & \\
\hline 4. Cannot say & 10 & $50 \%$ & 51 & $74 \%$ & \\
\hline $\begin{array}{l}\text { Is the risk for cardiovascular complications greater } \\
\text { for MODY-diabetics than people in general? }\end{array}$ & & & & & 0.0104 \\
\hline 1. Slightly greater & 6 & $30 \%$ & 12 & $18 \%$ & \\
\hline 2. Multifold & 4 & $20 \%$ & 8 & $12 \%$ & \\
\hline 3. Equal & 2 & $10 \%$ & 0 & & \\
\hline 4. Cannot say & 8 & $40 \%$ & 49 & $71 \%$ & \\
\hline $\begin{array}{l}\text { Are you aware of any diabetic complications in your } \\
\text { family? }\end{array}$ & & & & & 0.1236 \\
\hline 1. Yes & 10 & $50 \%$ & 24 & $35 \%$ & \\
\hline 2. No & 6 & $30 \%$ & 14 & $20 \%$ & \\
\hline 3. Cannot say & 4 & $20 \%$ & 31 & $45 \%$ & \\
\hline
\end{tabular}


Table 3 Reasons cited by the subjects in the follow-up questionnaire for taking either the diagnostic (diabetic subjects) or predictive gene test (unaffected subjects) from the MODY3 or HNPCC families

\begin{tabular}{|c|c|c|c|c|c|c|c|}
\hline \multirow[b]{3}{*}{ To reduce uncertainty } & \multicolumn{4}{|c|}{ Diagnostic test } & \multicolumn{3}{|c|}{ Predictive test } \\
\hline & \multicolumn{2}{|c|}{ MODY3 $(n=16)$} & \multicolumn{2}{|c|}{ MODY3 $(n=66)$} & \multirow{2}{*}{$\begin{array}{l}p \text { value } \\
<0.0001\end{array}$} & \multicolumn{2}{|c|}{ HNPCC $(n=271)$} \\
\hline & 12 & $75 \%$ & 52 & $78 \%$ & & 263 & $97 \%$ \\
\hline To clarify risk for children & 10 & $62 \%$ & 30 & $44 \%$ & 0.0005 & 185 & $68 \%$ \\
\hline To plan for the future & 5 & $31 \%$ & 36 & $53 \%$ & NS & 154 & $57 \%$ \\
\hline A doctor recommended it & 5 & $31 \%$ & 29 & $42 \%$ & NS & 132 & $49 \%$ \\
\hline Reproductive decisions & $2^{\mathrm{a}}$ & $16 \%$ & $14^{\mathrm{b}}$ & $24 \%$ & NS & $47^{\mathrm{c}}$ & $20 \%$ \\
\hline Employment decisions & $2^{\mathrm{a}}$ & $16 \%$ & $6^{\mathrm{b}}$ & $10 \%$ & NS & $33^{\mathrm{c}}$ & $14 \%$ \\
\hline Marital decisions & $1^{\mathrm{a}}$ & $8 \%$ & $4^{\mathrm{b}}$ & $7 \%$ & NS & $25^{\mathrm{c}}$ & $11 \%$ \\
\hline To help research & 1 & $1 \%$ & 0 & & NS & 2 & $1 \%$ \\
\hline Mean number of reasons/person & 2.4 & & 2.7 & & NS & 3.1 & \\
\hline
\end{tabular}

$N S$ not statistically significant $(P \geq 0.05)$

${ }^{\mathrm{a}} n=12$, excluding subjects older than 50 years

$\mathrm{b}_{n=58}$, excluding subjects older than 50 years

${ }^{c} n=224$, excluding subjects older than 50 years

pating and not participating in either the predictive or diagnostic part. This background data were also comparable to the Finnish population. The levels of university education and primary education were also the same as in the Finnish population ( 15 vs. $13 \%$; $p=\mathrm{NS}$ and 39 vs. $39 \%$ ) (Table 1).

Comparison of diabetic and non-diabetic subjects at risk of MODY3 Before the counselling, those with diabetes knew more about MODY3 and its treatment than their non-diabetic relatives did, but the late complications were rather unknown to both groups (Table 2). All but two knew about a hereditary form of diabetes in their family ( $95 \%$ of the diabetic vs. $91 \%$ of the non-diabetic, NS). A family member had informed most of the non-diabetic participants $(74 \%)$ of the risk of diabetes. Half of the diabetic subjects ( $55 \%$ vs. $33 \%$ of the non-diabetics, $p=0.135$ ) considered the inheritance of the susceptibility gene to be the worst feature of MODY3. The majority of both diabetic and non-diabetic subjects considered that the MODY3 gene test should be offered either in childhood (50 and $37 \%$ ) or as a teenager (30 and $37 \%$ ). Of the diabetic subjects, one $(5 \%)$ considered that testing should be postponed to adulthood vs. $4 \%$ of the non-diabetic subjects and the rest of the par-
Table 4 Comparison of the unaffected participants in MODY3 and HNPCC families and their pre-test risk perception

Data are given as mean $\pm \mathrm{SD}$ or $n(\%)$ ${ }^{\mathrm{a}} p<0.0001(d f=2)$

\begin{tabular}{|c|c|c|c|c|}
\hline & MODY3 & & HNPCC & \\
\hline Number of subjects & 69 & & 303 & \\
\hline \multirow[t]{2}{*}{ Age (years) } & $35.9 \pm 11.61$ & & $39.7 \pm 10.5$ & \\
\hline & Number & Percentage & Number & Percentage \\
\hline \multicolumn{5}{|l|}{ Gender } \\
\hline Male & 32 & $46 \%$ & 141 & $47 \%$ \\
\hline Female & 37 & $54 \%$ & 162 & $53 \%$ \\
\hline \multicolumn{5}{|l|}{ Having children } \\
\hline Yes & 39 & $56 \%$ & 214 & $71 \%$ \\
\hline No & 30 & $44 \%$ & 89 & $29 \%$ \\
\hline \multicolumn{5}{|l|}{ Highest level of education } \\
\hline Upper secondary or university & 25 & $37 \%$ & 119 & $39 \%$ \\
\hline Primary or vocational & 44 & $63 \%$ & 184 & $61 \%$ \\
\hline \multicolumn{5}{|l|}{ Marital status } \\
\hline Living with spouse or partner & 50 & $73 \%$ & 222 & $73 \%$ \\
\hline Widowed, single or divorced & 19 & $27 \%$ & 81 & $27 \%$ \\
\hline \multicolumn{5}{|l|}{ Employment status } \\
\hline Employed & 56 & $79 \%$ & 225 & $74 \%$ \\
\hline Unemployed or retired & 13 & $21 \%$ & 78 & $26 \%$ \\
\hline \multicolumn{5}{|l|}{ Pre-test risk perception ${ }^{\mathrm{a}}$} \\
\hline Low (below average) & 29 & $43 \%$ & 42 & $14 \%$ \\
\hline Intermediate (over average) & 30 & $44 \%$ & 218 & $72 \%$ \\
\hline High (almost certain) & 10 & $14 \%$ & 42 & $14 \%$ \\
\hline
\end{tabular}


Table 5 Satisfaction with taking the gene test 1 month after hearing the test result among the unaffected subjects in the MODY 3 and HNPCC families participating in the predictive study stratified according to the mutation carrier status

Data are given as $n(\%)$. The differences between the MODY3 and HNPCC groups were statistically non-significant

aThe exact phrasing was "would probably have taken test" in the MODY3 study and "would definitely have taken test" or "would probably have taken test" as separate alternatives in the

HNPCC study. These have been combined in the current analysis

\begin{tabular}{|c|c|c|c|c|c|c|c|c|}
\hline \multirow[t]{2}{*}{ Question } & \multicolumn{4}{|c|}{ MODY3 } & \multicolumn{4}{|c|}{ HNPCC } \\
\hline & \multicolumn{2}{|c|}{$\begin{array}{l}\text { Carrier } \\
(n=6)\end{array}$} & \multicolumn{2}{|c|}{$\begin{array}{l}\text { Non-carrier } \\
(n=58)\end{array}$} & \multicolumn{2}{|c|}{$\begin{array}{l}\text { Carrier } \\
(n=88)\end{array}$} & \multicolumn{2}{|c|}{$\begin{array}{l}\text { Non-carrier } \\
(n=181)\end{array}$} \\
\hline \multicolumn{9}{|c|}{ Are you satisfied with decision to take test? } \\
\hline 1. Extremely satisfied & 5 & $83 \%$ & 55 & $95 \%$ & 86 & $98 \%$ & 178 & $97 \%$ \\
\hline 2. Fairly satisfied & 1 & $17 \%$ & 3 & $5 \%$ & 2 & $2 \%$ & 5 & $3 \%$ \\
\hline 3. Uncertain & 0 & & 0 & & 0 & & 0 & \\
\hline 4. Rather dissatisfied & 0 & & 0 & & 0 & & 0 & \\
\hline 5. Extremely dissatisfied & 0 & & 0 & & 0 & & 0 & \\
\hline \multicolumn{9}{|l|}{ Do you trust the result? } \\
\hline 1. Trust completely & 5 & $83 \%$ & 56 & $97 \%$ & 86 & $98 \%$ & 160 & $87 \%$ \\
\hline 2. Trust hesitantly & 1 & $17 \%$ & 2 & $3 \%$ & 2 & $2 \%$ & 19 & $10 \%$ \\
\hline 3. Uncertain & 0 & & 0 & & 0 & & 0 & \\
\hline 4. Rather distrustful & 0 & & 0 & & 0 & & 0 & \\
\hline 5. Do not trust at all & 0 & & 0 & & 0 & & 0 & \\
\hline \multicolumn{9}{|c|}{$\begin{array}{l}\text { Now that you know the result, would you } \\
\text { have taken test in first place? }\end{array}$} \\
\hline 1. Would have taken test $\mathrm{a}^{\mathrm{a}}$ & 6 & $100 \%$ & 58 & $100 \%$ & 88 & $100 \%$ & 182 & $99 \%$ \\
\hline 2. Uncertain & 0 & & 0 & & 0 & & 1 & $1 \%$ \\
\hline 3. Would not have taken test & 0 & & 0 & & 0 & & 0 & \\
\hline
\end{tabular}

ticipants had no definite opinion. All diabetic and $80 \%$ of the non-diabetic subjects considered that children and their parents should jointly make the decision while $10 \%$ of the non-diabetic subjects would have let the children decide about the test by themselves ( $p=\mathrm{NS}$ ).

At the 1-month follow-up, the participants in both the diagnostic and the predictive part of the study were either extremely $(94 \%)$ or fairly $(6 \%)$ satisfied with their decision about the test. The main reasons for taking the test in both groups were to reduce uncertainty $(75 \%$ in the diagnostic and $78 \%$ in the predictive group), to clarify their children's risk and to plan for the future (Table 3 ). Those already diabetic seemed more concerned about the risk for their children $(62 \%)$ while the non-diabetic subjects were more concerned about their own future $(78 \%)$, but this difference was not statistically significant. About one third of the subjects in both groups reported that one of the reasons for taking the test was that a doctor had recommended it.

Comparison of non-affected subjects at risk of MODY3 or HNPCC The participants in the predictive MODY3 study and the HNPCC study were similar with respect to age, educational level as well as marital and employment status (Table 4). Also, the unadjusted baseline anxiety scores were similar between those at risk for MODY3 or HNPCC (mean STAI score 32.11 vs. 31.25, respectively). Before counselling, $44 \%$ of the MODY3 relatives compared with $72 \%$ of the HNPCC relatives had the correct pre-test risk perception, i.e. intermediate risk (above the average population risk). A higher proportion of members of the MODY3 families (43\%) considered the risk to get the disease to be low compared with those from the HNPCC families $(14 \%, p=0.0001)$. In both groups, $14 \%$ considered the risk to be very high, i.e. they were almost certain that they would get the disease. The lower pre-test risk per- ception did not affect the uptake of the gene test in the MODY3 group, which all except one took. All MODY3 relatives wanted to get their test results in connection with the counselling session instead of using the offered reflection time.

At the 1-month follow-up, both the MODY3 and HNPCC groups were satisfied with their decision about participating in the predictive gene test studies and trusted the result (Table 5). All subjects would have made again the same choice about taking the test.

Both groups reported almost the same reasons for taking the predictive tests. The most often cited reasons were to reduce the uncertainty or to clarify the risk for the children, but compared with the MODY3 group, those at risk for HNPCC more often wanted to reduce the uncertainty $(78 \%$ vs. $98 \%, p<0.0001)$ and to clarify the risk for children ( $44 \%$ vs. $68 \%, p=0.0005)$. Among those aged under 50 years marital, educational or reproductive reasons were not considered as important $(p=\mathrm{NS})$. Half of the participants considered that a doctor recommended the test (Table 3).

\section{Discussion}

The study shows a high uptake $(62 \%)$ of a predictive gene test in members of two extended Finnish MODY3 families. This was clearly higher than the uptake of a presymptomatic test for Huntington's disease (HD), $10 \%$ of those assumed to be aware of the availability of the test (Dr. M. Peippo, The Family Federation of Finland, personal communication), but somewhat lower than that of a predictive test for HNPCC in Finland (75\%) [15]. Many of the subjects might have considered themselves to be beyond the most critical age to get ill as $50 \%$ of the MODY3 gene carriers get diabetes before the age of 20 
[20]. Optimally, predictive testing should be offered before clinical onset of diabetes, i.e. before puberty. Also, most participants in the study considered childhood or puberty as the best. However, before starting predictive testing in childhood, ethical issues and counselling strategies have to be carefully evaluated in that age group to ensure that the subjects understand the implications of the tests and are aware of their right to refuse participation.

A diagnostic test confirms the diagnosis and provides a basis for the counselling. A predictive test divides the members of a family into those who need clinical surveillance and those who can be released from it. The impact of testing is quite different in the three diseases. HD is a severe debilitating disease without prevention or treatment. The main benefit of testing is that the non-carriers can be freed from unnecessary worry and follow-up, which also applies to HNPCC and MODY. In case of HNPCC, correct prediction benefits cancer prevention as tumours can be removed at an early stage during follow-up with regular colonoscopies. Thus, the test has direct implications for the individual's outcome. Genetic prediction of MODY3 does not lead to prevention of diabetes and the long-term benefits of early treatment are unsure. It may help in preventing diabetic complications and foetal problems. Also, it has implications for treatment choices, which again may lead to a better glycaemic control. However, at present there are no evidence-based data to support this. The alternative to genetic testing in case of HNPCC is follow-up with colonoscopy at 2-3 year intervals [28] or either oral glucose tolerance test (OGTT) or fasting glucose combined with measurement of post-prandial glucose or $\mathrm{HbA} 1 \mathrm{c}$ in case of MODY3. This follow-up scheme is also used for mutation carriers. Also, they are instructed to measure blood glucose in conjunction with febrile infections and contact a maternity clinic before pregnancy as both conditions can result in insufficient insulin secretion and hyperglycaemia through a decrease in insulin sensitivity. The cost of one gene test of a known mutation is roughly 85 Euros. Sequencing of MODY1, 2 and 3 to identify a previously unknown mutation is 350 Euros. Thus, identification of a family mutation and then screening for it in the rest of the family leads to considerable savings compared to an annual checkup of all family members even when the cost of counselling is taken into consideration. One possible contributor to the somewhat lower participation rate in the MODY3 compared with the HNPCC study is that diabetes might not be considered as severe and frightening as cancer, diminishing the impact of a predictive test on the person's life. The HNPCC group more often overestimated the pre-test risk in comparison with the MODY3 group, but the pre-test risk perception was not associated with test uptake in either group. Also, the subjects at risk of HNPCC were significantly more worried about their future and the risk for their children than those at risk of MODY3. In general, the stated reasons for taking the test were quite similar in these two conditions, the most important ones being reduction of uncertainty, planning for the future and clarifying the risk for the children. Somewhat surprisingly, marital, repro- ductive or educational plans were not cited often among those aged $<50$ years.

There was no clear difference between the groups in the contentment with the test. The participants were very pleased with their decision to take the test and they also trusted the results. This suggests that the tests were able to provide answers to the questions the participants had in mind. The risk for their children was clarified, the uncertainty ended and several of them were released from surveillance. For those already diabetic, the diagnostic test offered an accurate diagnose and the implications of it. They also became aware of the potential risk for their children.

We offered counselling and test results to both affected and unaffected individuals. Only one third of diabetic men participated while there was no difference in the participation rate of diabetic or non-diabetic women. This may reflect that the already affected participants wanted to ensure their diagnosis considering its implications for their descendants. Of note, most of the participants had already participated in different phases of the Botnia study. Thus the study may be biased towards people who, in general, have a positive attitude towards medical research. Another limitation to the generalizability of the results is that the participants came from only two, albeit quite extended, pedigrees. This may explain the lack of significant socioeconomic differences between participants and non-participants, which is in contrast to a previous study showing an association between test uptake and higher education, often related to a better economic situation [16]. However, the latter may be an important factor in an insurance based health-care system while a predictive test for a treatable disease may be more readily accepted in Finland with mainly publicly funded health care. Also, according to the Finnish legislation the employers have no right to request gene tests or results of previous tests.

The high participation rate supports the suggestion that the Finnish population in general is confident in medical research and health care as well as genetic testing [29]. The uptake rate for genetic screening of neonates for diabetes risk has been as high as 94\% [30] and genetic clinics have encountered high uptake of cascade screening in cancer families (Dr. Kristiina Aittomäki, Department of Medical Genetics, University of Helsinki, personal communication).

Testing of the above kind should always be based on informed consent to ensure that people understand the implications of the tests and are aware of their right to refuse participation. Clinical geneticists offer such services as non-directively as possible, but they counsel only a minority of patients. How and what health professionals communicate with patients is of utmost importance. The fact that subjects from both MODY3 and HNPCC families were motivated to take the test by their doctor's recommendation supports the findings of Vernon that advice from a physician was an important factor in preventive health behaviour [31]. There are some undeniable benefits in predictive genetic testing in diseases like MODY3 and HNPCC, and we should try to find the proper way to offer 
tests to different groups in society to ensure their awareness of these benefits, but simultaneously to remain non-directive. It has been shown for cystic fibrosis that a test offered directly from health professionals results in a higher uptake than if the test was merely known to be available [32, 33].

In conclusion, both diagnostic and predictive genetic testing for MODY3 was well accepted. In principle, genetic testing should be offered to patients from families with young-onset diabetes in at least two generations (the classical MODY criteria) but possibly even to sporadic patients with atypical diabetes. However, until highthroughput methods, like MODY chips, are available, the cost of testing will limit availability, as there are several possible mutations to screen. The situation is different when an index case in a family has been diagnosed with genetically confirmed MODY. Then genetic counselling and testing for the known mutation should be offered to at least those first-degree relatives who are younger than 50-60 years of age. Counselling should be an essential part of the process to allow the subjects to make an informed and autonomous decision.

Acknowledgements The Botnia Research Group is acknowledged for recruiting and clinically studying the subjects and Ms. Taina Miikkulainen and Ms. Leena Toivanen for secretarial help. The study was financially supported by grants from the Academy of Finland, the Finnish Diabetes Research Foundation, the Sigrid Juselius Foundation, the Folkhalsan Research Foundation, the Novo Nordisk Foundation, the Jalmari and Rauha Ahokas Foundation, and EC (BM4-CT95-0662, GIFT).

\section{References}

1. Yamagata K, Furuta H, Oda A et al (1996) Mutations in the hepatic nuclear factor 4 a gene in maturity onset diabetes of the young (MODY1). Nature 384:458-460

2. Yamagata K, Oda A, Kaisaki PJ et al (1996) Mutations in the hepatic nuclear factor 1 a gene in maturity onset diabetes of the young (MODY3). Nature 384:455-458

3. Horikawa Y, Iwasaki N, Hara M et al (1997) Mutation in hepatocyte nuclear factor-1 beta gene (TCF2) associated with MODY. Nat Genet 17:384-385

4. Velho G, Blanche H, Vaxillaire M et al (1997) Identification of 14 new glucokinase mutations and description of the clinical profile of 42 MODY-2 families. Diabetologia 40:217-224

5. Stoffers DA, Ferrer J, Clarke WL, Habener JF (1997) Earlyonset type-II diabetes mellitus (MODY4) linked to IPF1. Nat Genet 17:138-139

6. Malecki MT, Jhala US, Antonellis A et al (1997) Mutations in NEUROD1 are associated with the development of type 2 diabetes mellitus. Nat Genet 23:323-328

7. Glucksmann MA, Lehto M, Tayber O et al (1997) Novel mutations and a mutational hotspot in the MODY3 gene. Diabetes 46:1081-1086

8. Craufurd D, Dodge A, Kerzin-Storrar L, Harris L (1989) Uptake of presymptomatic predictive testing for Huntington's disease. Lancet 2:603-605
9. Tibben A, Frets PG, van de Kamp JJ et al (1993) On attitudes and appreciation 6 months after predictive DNA testing for Huntington disease in the Dutch program. Am J Med Genet 48:103-111

10. Kinzler K, Vogelstein B (1996) Lessons from hereditary colorectal cancer. Cell 87:159-170

11. Peltomaki P, de la Chapelle A (1997) Mutations predisposing to hereditary nonpolyposis colorectal cancer. Adv Cancer Res $71: 93-119$

12. Aarnio M, Mecklin J-P, Aaltonen LA, Nystrom-Lahti M, Järvinen HJ (1995) Life-time risk of different cancers in hereditary non-polyposis colorectal cancer (HNPCC) syndrome. Int J Cancer 64:430-433

13. Lynch HT, Smyrk TC, Watson P et al (1993b) Genetics, natural history, tumor spectrum, and pathology of hereditary nonpolyposis colorectal cancer: an updated review. Gastroenterology 104:1535-1549

14. Dunlop MG, Farrington SM, Carothers AD et al (1997) Cancer risk associated with germline DNA mismatch repair gene mutations. Hum Mol Genet 6:105-110

15. Aktan-Collan K, Mecklin J-P, Järvinen H et al (2000) Predictive genetic testing for hereditary non-polyposis-colorectal-cancer: uptake and long-term satisfaction. Int J Cancer (Pred Oncol) 89:44-50

16. Lerman C, Hughes C, Trock BJ et al (1999) Genetic testing in families with hereditary nonpolyposis colon cancer. JAMA 281:1618-1622

17. Lehto M, Tuomi T, Mahtani MM et al (1997) Characterization of the MODY3 phenotype. Early-onset diabetes caused by an insulin secretion defect. J Clin Invest 99:582-591

18. Tripathy D, Carlsson $\AA$-L, Lehto M, Isomaa B, Tuomi T, Groop L (2000) Insulin secretion and insulin sensitivity in diabetic subgroups: studies in the prediabetic and diabetic state. Diabetologia 43:1476-1483

19. Pearson ER, Starkey BJ, Powell RJ, Gribble FM, Clark PM, Hattersley AT (2003) Genetic cause of hyperglycaemia and response to treatment in diabetes. Lancet 362:1275-1281

20. Honkanen EH, Isomaa B, Sarelin L, Lehto M, Groop L, Tuomi T (2002) Onset of glucose intolerance in MODY3 Pro291fsInsC mutation carriers coincides with pubertal yearsa prospective follow-up study. Diabetologia 45:A129

21. Isomaa $B$, Henricsson M, Lehto M et al (1998) Chronic diabetic complications in patients with MODY3 diabetes. Diabetologia 41:467-473

22. Klupa T, Warram J, Antonellis A et al (2002) Determinants of the development of diabetes (MODY3) in carriers of HNF-1 mutations: evidence for a parent of origin effect. Diabetes Care 25:2292-2301

23. Stride A, Shepherd M, Frayling T et al (2002) Intra-uterine hyperglycemia is associated with an earlier diagnosis of diabetes in hepatocyte nuclear factor-1 alpha gene mutation carriers. Diabetes Care 25(12):2287-2291

24. Huggins M, Bloch M, Wiggins S et al (1992) Predictive testing for Huntington disease in Canada: adverse effects and unexpected results in those receiving a decreased risk. Am J Med Genet 42:508-515

25. Shepherd M, Hattersley AT, Sparkes AC (2000) Predictive genetic testing in diabetes: a case study of multiple perspectives. Qual Health Res 10:242-259

26. Lehto M, Tuomi T, Mahtani M et al (1997) Characterization of the MODY3 phenotype: early-onset diabetes caused by an insulin secretion defect. J Clin Invest 99:582-591

27. Spielberger CRG, Lushene R (1970) Manual for the state trait anxiety inventory. Consulting Psychologist Press, Palo Alto

28. Vasen HF (2000) Clinical diagnosis and management of hereditary colorectal cancer syndromes. J Clin Oncol 18:81S$92 \mathrm{~S}$ 
29. Hietala M, Hakonen A, Aro AR, Niemela P, Peltonen L, Aula P (1995) Attitudes toward genetic testing among the general population and relatives of patients with a severe genetic disease: a survey from Finland. Am J Hum Genet 56:1493-1500

30. Kupila A, Simell P, Arvilommi T et al (2001) Feasibility of genetic and immunological prediction of Type 1 diabetes in a population-based birth cohort. Diabetologia 44:290-297
31. Vernon S (1997) Participation in colorectal cancer screening: a review. J Natl Cancer Inst 89:1406-1422

32. Bekker H, Modell M, Denniss G et al (1993) Uptake of cystic fibrosis in primary care: supply push or demand pull. Br Med J 306:1584-1586

33. Tambor ES, Bernhardt BA, Chase GA et al (1994) Offering cystic-fibrosis-carrier screening to an HMO population: factors associated with utilization. Am J Hum Genet 55:626-637 